\title{
Synthesis of an $O$-alkynyl-chitosan and its chemoselective conjugation with a PEG-like amino-azide through click chemistry
}

\author{
José Ricardo Oliveira ${ }^{\mathrm{a}, \mathrm{b}}$, M. Cristina L. Martins ${ }^{\mathrm{a}}$, Luís Mafrac ${ }^{\mathrm{c}}$, Paula Gomes ${ }^{\mathrm{a}, *}$ \\ a CIQ-UP, Departamento de Química e Bioquímica, Faculdade de Ciências, Universidade do Porto, Rua do Campo Alegre 687, 4169-007 Porto, Portugal \\ b INEB - Instituto de Engenharia Biomédica, Divisão de Biomateriais, Universidade do Porto, Rua do Campo Alegre 823, 4150-180 Porto, Portugal \\ c Department of Chemistry, CICECO, University of Aveiro, 3810-193 Aveiro, Portugal
}

\section{A R T I C L E I N F O}

\section{Article history:}

Received 2 March 2011

Received in revised form 22 July 2011

Accepted 25 July 2011

Available online 3 August 2011

\section{Keywords:}

Azide-alkyne coupling

Bioadhesion

Biomaterials

Chitosan

click chemistry

FTIR

Huisgen's 1,3-dipolar cycloaddition

Size-exclusion chromatography

Solid-state NMR

XPS

\begin{abstract}
A B S T R A C T
$\mathrm{N}$-Phthaloyl-chitosan $\mathrm{O}$-prop-2-ynyl carbamate was prepared as a biopolymer amenable to undergo chemoselective conjugation by azide-alkyne coupling, while allowing upturn of chitosan's amines after dephthaloylation. $N$-phthaloylchitosan was prepared according to previously described methods and, due to its low solubility in current organic media, subsequent modifications were run in heterogeneous conditions. Activation of hydroxyls with carbonyl-1,1'-diimidazole and coupling to propargylamine yielded $\mathrm{N}$-phthaloyl-chitosan $O$-prop-2-ynyl carbamate, then coupled to a model PEG-like azide by azide-alkyne coupling, giving the expected triazolyl conjugate. $\mathrm{N}$-Dephthaloylation allowed recovery of the free amines, responsible for chitosan's bioadhesion and tissue-regeneration properties.

The structures of all polymers were confirmed by Fourier-transformed infra-red (FT-IR) and X-ray photoelectron (XPS) spectroscopies, as well as by solid-state nuclear magnetic resonance (SSNMR). All chitosan derivatives were poorly soluble in both aqueous and organic media, which makes them suitable for topical applications or for removal of toxic substances from either the gastric intestinal tract or environmental sources.
\end{abstract}

(ㄷ) 2011 Elsevier Ltd. All rights reserved.

\section{Introduction}

Some of the most appealing characteristics of chitosan are its bioadhesive properties and its ability to promote cell proliferation and, consequently, tissue regeneration (Berger, Reist, Mayer, Felt, \& Gurny, 2004; Berger, Reist, Mayer, Felt, Peppas, et al., 2004). These properties of chitosan are of outmost importance for biomedical engineering and are enhanced upon decreasing the polymer's degree of acetylation (Amaral, Lamghari, Sousa, Sampaio, \& Barbosa, 2005), meaning that such properties are intrinsically related with the polymer's amino groups that are cationic in acidic-neutral media (Batista, Pinto, Gomes, \& Gomes, 2006), like in physiological fluids. Many chemical modifications have been carried out on chitosan's D-glucosamine units, conferring to the new materials surprising properties and additional possibilities of engaging in a wide range of chemical reactions for diverse applications (Muzzarelli, 1988; Kurita et al., 2002; Holappa, Hjálmarsdóttir, et al., 2006; Holappa, Nevalainen, Soininen, Másson, \& Järvinen, 2006b; Rúnarsson, Holappa, Jónsdóttir, Steinsson, \& Másson, 2008; Rúnarsson et al.,

\footnotetext{
* Corresponding author. Tel.: +351 220402563; fax: +351220402659.

E-mail address: pgomes@fc.up.pt (P. Gomes).
}

2010), e.g., biomedical engineering and/or drug delivery (Anitha et al., 2011; Iqbal, Sarti, Perera, \& Bernkop-Schnürch, 2011; Molnár, Barbu, Lien, Górecki, \& Tsibouklis, 2010; Muzzarelli, 2009, 2011). However, most chitosan modifications described in the literature have been carried out exclusively or inclusively at the polymer's primary amino groups, which is undesirable for applications in which the polymer's amine-dependent bioadhesion and/or $\mathrm{pH}$ dependent properties should have a key role. In view of this, we have worked on the synthesis and characterization of a novel chitosan derivative that conserves the primary amine groups unchanged, while being selectively modified at its primary alcohol function in order to bear an alkyne moiety amenable to undergo further modifications by well-known organic reactions, e.g., Huisgen 1,3-dipolar cycloaddition (a "click reaction" corresponding to an azide-alkyne coupling) (Kolb, Finn, \& Sharpless, 2001) or Sonogashira coupling (Chinchilla \& Nájera, 2007). These reactions may serve, among other purposes, for facile chitosan conjugation with drugs and other bioactive molecules, like azide-modified peptides or sugars, already available in the market or easily produced by current organic synthesis procedures (Lahann, 2009). Therefore, a selectively $N$-protected $O$-alkynylated chitosan was prepared by straightforward methods and submitted to a test azide-alkyne coupling reaction with a commercial azide (PEG-like azide) to serve as proof-of-concept, as herein described. 


\section{Materials and methods}

\subsection{Chemicals}

Chitosan was obtained from France-Chitine. Phthalic anhydride, tetrahydrofuran (THF), 1,1'-carbonyldiimidazole (CDI), propargylamine, copper (II) acetate, sodium ascorbate, ethylenediamine tetraacetic acid (EDTA) disodium salt, hydrazine monohydrate, and 11-azido-3,6,9-trioxaundecan-1-amine were from Sigma-Aldrich. Potassium bromide (KBr) and all remaining organic chemicals and solvents were from Merck.

\subsection{Purification of commercial chitosan}

Chitosan was purified by the reprecipitation method (Crompton et al., 2007). Briefly, $1 \mathrm{~g}$ of chitosan powder was pre-hydrated in $197.92 \mathrm{ml}$ of ultrapure water, for $24 \mathrm{~h}$ at $4^{\circ} \mathrm{C}$ under slow magnetic stirring. Then, acetic acid $(2.28 \mathrm{ml})$ was added, and the slurry left overnight at room temperature. After complete dissolution, the resulting gel was filtered through a 20 micrometer pore size filter to remove undissolved or gelatinous particles. Chitosan was then precipitated through dropwise addition of $1 \mathrm{M}$ aqueous $\mathrm{NaOH}$, while stirring. Finally, the regenerated chitosan was washed with ultrapure water by centrifugation until neutrality, freeze-dried and grounded in a laboratory mill to yield a fine powder.

The degree of acetylation and molecular weight of the purified chitosan were determined using FT-IR Fourier transform infrared spectroscopy (see Section 2.8) and high perfomance size-exclusion chromatography (HP-SEC, see Section 2.10), respectively.

\subsection{Preparation of N-phthaloyl-chitosan (2)}

The chemical route towards the target chitosan derivative is given in Scheme 1 and began with the synthesis of $\mathrm{N}$-phthaloylchitosan (2), according to the method developed by Kurita, Ikeda, Yoshida, Shimojoh, and Harata (2002). Briefly, purified chitosan, $1(1.0 \mathrm{~g}, 6.20 \mathrm{mmol})$ and phthalic anhydride $(2.76 \mathrm{~g}, 18.60 \mathrm{mmol})$ were suspended in $30 \mathrm{ml}$ DMF containing $5 \%(\mathrm{v} / \mathrm{v})$ water and the mixture heated at $120^{\circ} \mathrm{C}$ with magnetic stirring, under argon atmosphere. After $8 \mathrm{~h}$, the mixture was cooled to room temperature and poured into ice water. The resulting pale tan precipitate was collected on a G4 filter funnel, thoroughly washed with cold methanol, and dried in air to give $1.4 \mathrm{~g}$ of $\mathrm{N}$-phthaloyl-chitosan (2).

\subsection{Preparation of N-phthaloyl-chitosan O-prop-2-ynyl carbamate (3)}

$N$-phthaloyl-chitosan 2 (0.6 g, $2 \mathrm{mmol})$, pre-washed with THF, was suspended in $9 \mathrm{ml}$ of $30 \mathrm{mg} / \mathrm{ml} \mathrm{CDI}$ in THF, and the slurry taken to $40^{\circ} \mathrm{C}$ under argon atmosphere and gentle magnetic stirring. After $5 \mathrm{~h}$, the solid fraction was collected on a G4 filter funnel and washed thoroughly with THF to remove CDI excess. The precipitate was transferred to a new flask to which were added $6 \mathrm{ml}$ of $30 \mathrm{mg} / \mathrm{ml}$ propargylamine in THF. The slurry was gently stirred at room temperature for $24 \mathrm{~h}$, after which the solid fraction was collected on a G4 filter funnel, washed with methanol and dried in air to give $\mathrm{N}$-phthaloyl-chitosan O-prop-2-ynyl carbamate (3).

\subsection{Preparation of N-phthaloyl-chitosan O-(11-amino-3,6,9-undecan)triazolyl carbamate (4)}

$\mathrm{N}$-Phthaloyl-chitosan $\quad$-prop-2-ynyl carbamate $3 \quad(0.4 \mathrm{~g}$ $0.9 \mathrm{mmol})$, copper acetate $(0.06 \mathrm{~g}, 0.45 \mathrm{mmol})$, sodium ascorbate $(0.12 \mathrm{~g}, 0.64 \mathrm{mmol})$ and the PEG-like azide (11-azido-3,6,9trioxaundecan-1-amine) $(0.2 \mathrm{~g}, 0.9 \mathrm{mmol})$ were mixed in $16 \mathrm{ml}$ of tert-butanol $/ \mathrm{H}_{2} \mathrm{O}(1: 1, \mathrm{v} / \mathrm{v})$ and the mixture left overnight under gentle magnetic stirring, at room temperature. The solid fraction, $\mathrm{N}$-phthaloyl-chitosan $\mathrm{O}$-(11-amino-3,6,9-undecan)triazolyl carbamate 4, was collected on a G4 filter funnel and thoroughly washed first with $0.1 \mathrm{M}$ EDTA and then with methanol, and finally dried in air.

\subsection{Removal of the N-phthaloyl protecting group from 4: synthesis of chitosan 0-(11-amino-3,6,9-undecan)triazolyl carbamate (5)}

$\mathrm{N}$-Phthaloyl-chitosan 0 -11-amino-3,6,9-undecantriazolyl carbamate $4(0.15 \mathrm{~g}, 0.25 \mathrm{mmol})$ was reacted with hydrazine monohydrate $(1 \mathrm{ml}, 18 \mathrm{mmol})$ in $10 \mathrm{ml}$ ethanol, at $40^{\circ} \mathrm{C}$ with gentle stirring. After $18 \mathrm{~h}$, the solid fraction was collected by centrifugation, thoroughly washed with ethanol and water and freeze-dried to give the deprotected chitosan $O$-(11-amino-3,6,9undecan)triazolyl carbamate $\mathbf{5}$.

\subsection{XPS analysis}

Chitosan, 1, and its derivatives 3-5 were analysed by XPS. Samples were prepared by compressing the powdered polymers into $1 \mathrm{~mm}$-thick pellets. Measurements were carried out on a VG Scientific ESCALAB 200A spectrometer using aluminum (15kV) as a radiation source. Photoelectrons were analysed at a take-off angle normal to the interface. Survey spectra were collected over the $0-1100 \mathrm{eV}$ range with analyser pass energy of $50 \mathrm{eV}$. Highresolution $\mathrm{C} 1 \mathrm{~s}, \mathrm{~N} 1 \mathrm{~s}$ and $\mathrm{O} 1 \mathrm{~s}$ spectra were collected with analyser pass energy of $20 \mathrm{eV}$. The binding energy scales were referenced by setting the $\mathrm{C} 1 \mathrm{~s}$ binding energy to $285.0 \mathrm{eV}$. Spectra were fitted using the XPSPEAK (version 4.1) software.

\subsection{FT-IR analysis}

FT-IR spectra of chitosan, 1, and its derivatives 3-5, were obtained using a Perkin-Elmer System 2000 FT-IR spectrometer. All the samples were recorded as $\mathrm{KBr}$ pellets prepared by blending $2 \mathrm{mg}$ of the powdered polymer, previously dried overnight at $60^{\circ} \mathrm{C}$ under reduced pressure, with $200 \mathrm{mg} \mathrm{KBr}$, previously dried at $105^{\circ} \mathrm{C}$ for $24 \mathrm{~h}$. The infrared spectra were obtained by accumulation of 100 interferograms, at $4 \mathrm{~cm}^{-1}$ spectral resolution, between 4000 and $400 \mathrm{~cm}^{-1}$ and after nitrogen purge of the sample compartment for $2 \mathrm{~min}$ to minimize bands that could arise from residual air components $\left(\mathrm{CO}_{2}\right.$ and $\left.\mathrm{H}_{2} \mathrm{O}\right)$. Spectra were fitted using the Spectrum $\mathrm{GX}$ FT-IR (version 5.3) software. The DA was estimated according to the method proposed by Brugnerotto et al. (2001), where the amide III (C-N stretching vibration) band $\left(1320 \mathrm{~cm}^{-1}\right)$ was used as the analytical band and the band at $1420 \mathrm{~cm}^{-1}$ (in plane $\mathrm{O}-\mathrm{H}$ deformation vibration) was used as the internal reference band.

\subsection{SSNMR measurements}

Carbon-13 cross-polarization/magic angle spinning nuclear magnetic resonance $\left({ }^{13} \mathrm{C}-\mathrm{CP} / \mathrm{MAS} \mathrm{NMR}\right)$ spectra were recorded on a 9.4 T WB $\left(400 \mathrm{MHz},{ }^{1} \mathrm{H}\right.$ Larmor frequency) Bruker Avance spectrometer (DSX model). A $4 \mathrm{~mm}$ double-resonance magic angle spinning probe was employed at $400.1\left({ }^{1} \mathrm{H}\right)$ and $100.6 \mathrm{MHz}\left({ }^{13} \mathrm{C}\right)$ Larmor frequencies. Samples were spun in $\mathrm{ZrO}_{2}$ rotors using a spinning rate of $12 \mathrm{kHz} .{ }^{13} \mathrm{C}-\mathrm{CP} / \mathrm{MAS}$ NMR spectra were recorded using a ramp step (varying from $100 \%$ to $50 \%$ in amplitude using 100 points); contact time: $1.5 \mathrm{~ms} ;{ }^{1} \mathrm{H} 90^{\circ}$ excitation pulse: $3.75 \mu \mathrm{s} ;{ }^{1} \mathrm{H}$ and ${ }^{13} \mathrm{C}$ radiofrequency field strength for cross polarization was set to $87 \mathrm{kHz}$ and $68 \mathrm{kHz}$, respectively; number of scans: $1 \mathrm{k}$; recycle delay: $5 \mathrm{~s}$. TPPM-15 decoupling (Bennett et al., 1995) was employed during the signal acquisition using a $4.8 \mu$ s pulse length for the basic TPPM 

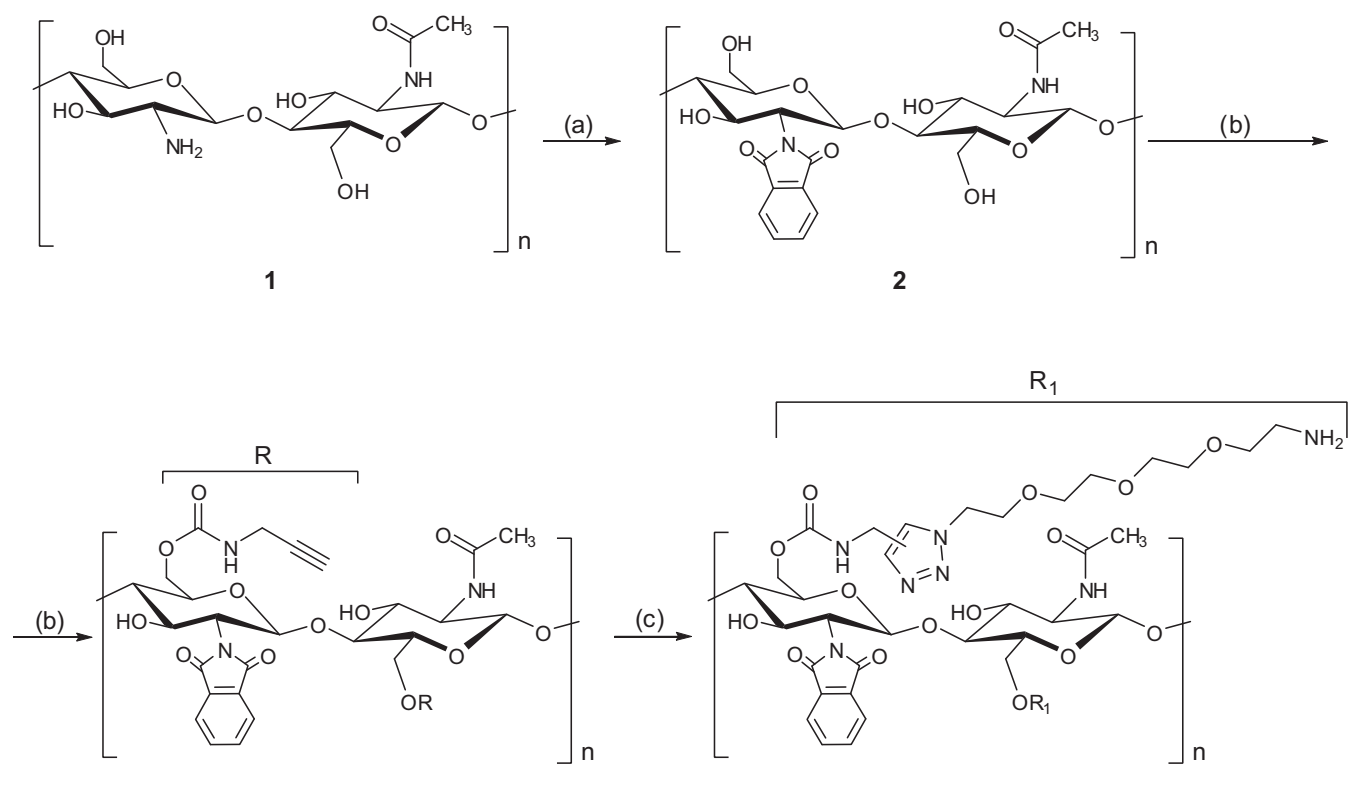

3

4

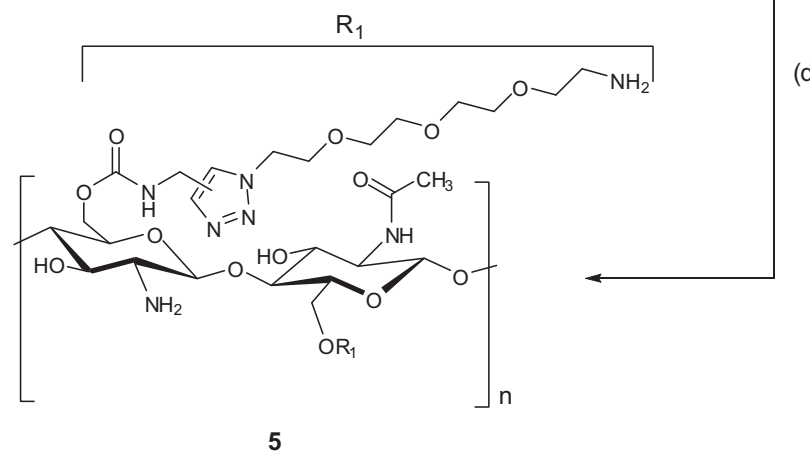

(d)

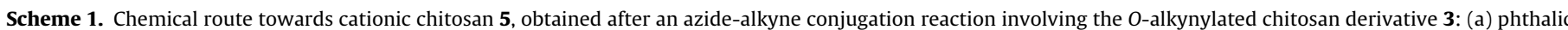

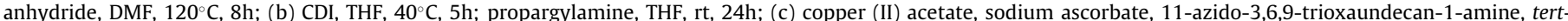
butanol/ $\mathrm{H}_{2} \mathrm{O}$, rt, overnight; (d) hydrazine monohydrate, $\mathrm{H}_{2} \mathrm{O}, 100^{\circ} \mathrm{C}, 18 \mathrm{~h}$. For simplicity, only modified monomers of $\mathbf{2 - 5}$ are considered in the Scheme.

pulse unit along the ${ }^{1} \mathrm{H}$ channel, employing a ${ }^{1} \mathrm{H}$ radio-frequency field strength of $100 \mathrm{kHz}$.

${ }^{13} \mathrm{C}$ chemical shifts are quoted in parts per million $(\mathrm{ppm})$ and calibrated with respect to the external reference, glycine $(\mathrm{C}=\mathrm{O}$, $176.03 \mathrm{ppm})$.

\subsection{HP-SEC measurements}

The molecular weight of chitosan (1) was determined by HP-SEC using a modular system composed of an isocratic pump (K1001, Knauer), a vacuum degasser (Wellchrom 2 channel K-5002, Knauer), a viscometer/right angle laser light scattering (RALLS) dual detector (T60A Viscotek) and a refractive index detector (K-2301 Knauer) operating the same wavelength as the RALLS detector $(670 \mathrm{~nm})$. PL aquagel-OH mixed columns were used for separations. The samples were dissolved in the mobile phase $(0.5 \mathrm{M}$ acetic acid/0.2 M sodium acetate with $0.01 \%(\mathrm{v} / \mathrm{v}) \mathrm{NaN}_{3}$ ) at $1 \mathrm{mg} / \mathrm{ml}$, filtered and injected through a manual injection valve equipped with a $100 \mu \mathrm{l}$ loop. The flow-rate was maintained at $1.0 \mathrm{ml} / \mathrm{min}$.

\section{Results and discussion}

Chitosan (1) obtained after purification of the commercial powder presented a molecular weight of $283.000-472.000$ and a DA of $16 \%$, determined as described in the previous sections. This starting material was then subjected to chemical modifications depicted in Scheme 1. The stepwise procedure employed is necessary since the reactivity of chitosan's primary amines is considerably higher than that of the primary hydroxyls, so $\mathrm{N}$ protection followed by $O$-activation is a suitable approach. Chitosan amine groups were protected by $\mathrm{N}$-phthaloylation to yield $\mathbf{2}$, as $\mathrm{N}$-phthaloylation is now a current and versatile procedure whenever chemoselective $O$-modification of the biopolymer is desirable (Kurita et al., 2002; Kurita, Yoshida, \& Umemura, 2010). The $N$ phthaloyl derivative $\mathbf{2}$ was poorly soluble in a wide range of common organic and aqueous/organic solvents, as expected from previous findings by Kurita et al. (2002). These authors ascribed such phenomenon to an increased crystallinity of the modified polymer, which could be confirmed by us through dephthaloylation (according to the procedure in 2.6) of $N$-phthaloylchitosan (2) back to its "unmodified" form, which was found to be no longer soluble in acidic aqueous media, as was the original polymer (1). 
The low solubility of $\mathbf{2}$ made us carry out subsequent reactions under heterogeneous conditions, as recent literature shows that chemical modifications of chitosan can been successfully achieved under such conditions (Elkholy, Khalil, \& Elsabee, 2011; Li, Yuan, Gu, \& Re, 2010; Shen, Ji, Yang, \& Zheng, 2007; Wan, Gao, \& Li, 2010).

$N, N^{\prime}$-Carbonyldiimidazole (CDI) was used for activation of hydroxyls in $\mathbf{2}$ towards subsequent coupling with propargylamine to yield 3; CDI is a cheap and efficient coupling agent used in industrial production of peptides (Montalbetti \& Falque, 2005), which has been successfully employed in the modification of polysaccharides as cellulose, dextran or chitosan for multiple applications (Chirachanchai, Lertworasirikul, \& Tachaboonyakiat, 2001; Oh, Lee, \& Park, 2009; Önal \& Telefoncu, 2003). Propargylamine was selected as the alkyne donor, as it provides a hydrophilic and stable, yet chemo-reversible, carbamate group linked to the terminal alkyne through a flexible methylene. Obviously, this approach is applicable to other alkynyl-amines for tailored spacer size and flexibility. The structures of chitosan derivatives $\mathbf{2}$ and $\mathbf{3}$ were confirmed, as demonstrated through the use of a toolbox of spectroscopic techniques, discussed further below.

To offer proof-of-concept regarding the ability of polymer 3 to undergo a chemoselective coupling to an azide moiety, we have submitted this polymer to a Huisgen's 1,3-dipolar cycloaddition with 11-azido-3,6,9-trioxaundecan-1-amine, taken as representative of any azide-modified biomolecule (drug, peptide, etc.). This test azide was chosen given its commercial availability, reasonable cost, medium size and overall hydrophilic character (PEG-like chain with a terminal primary amine). Recent reports describe successful application of the azide-alkyne coupling reaction to create novel chitosan-based biomaterials (Li et al., 2010; Yuan, Zhao, Gu, \& Ren, 2010; Yuan, Li, Gu, Cao, \& Ren, 2011; Yuan, Zhao, Gu, Ren, \& Ren, 2011; Zhang et al., 2011). In most cases, the classical $\mathrm{Cu}(\mathrm{I}) / N, N, N^{\prime}, N^{\prime \prime}, N^{\prime \prime}$-pentamethyldiethylenetriamine (PMDETA) system has been used (Li et al., 2010; Yuan et al., 2010; Yuan, Li, et al., 2011; Yuan, Zhao, et al., 2011) to promote the click reaction, as some authors have previously reported that in situ generation of $\mathrm{Cu}(\mathrm{I})$ by means of the $\mathrm{Cu}(\mathrm{II}) /$ ascorbate system leads to severe depolimerization of the chitosan backbone (Lallana, Fernández-Megía, \& Riguera, 2009; Kulbokaite et al., 2009). Interestingly, no such problem was reported on a latest work where the $\mathrm{Cu}(\mathrm{II}) /$ ascorbate system has been used to create chitosan-based microcapsules through multilayer assembly by click chemistry (Zhang et al., 2011). Anyway, we started by using the $\mathrm{Cu}(\mathrm{I}) / \mathrm{PMDETA}$ system, but soon discarded this option due to the inefficient removal of excess copper from the polymer matrix, even after extensive workup with EDTA (data not shown). This problem, also reported by other authors (Lallana, Fernández-Megía \& Riguera, 2009), was not observed when using $\mathrm{Cu}$ (II)/ascorbate, which therefore became our system of choice. In order to avoid or at least minimize the depolimerization problems allegedly associated to $\mathrm{Cu}$ (II)/ascorbate, we have run the cycloaddition reaction at room temperature for no longer than $12 \mathrm{~h}$.

As demonstrated by structural analyses (see discussion below), the cycloaddition occurred as expected to yield 4 . The low solubility of this product in a wide range of aqueous buffers and aqueous/organic eluents, prevented us to accurately determine the polymer's molecular weight by HP-SEC. Nonetheless, the insolubility of 4 indirectly suggests that this is still a high molecularweight polymer. Furthermore, based on a previous work by Cabrera and Van Cutsem, who used matrix-assisted laser desorption ionization-time-of-flight mass spectrometry (MALDI-TOF MS) to detect chitooligosaccharides (Cabrera \& Van Cutsem, 2005), we used this technique to analyse polymer $\mathbf{4}$, but no peaks were found below $100 \mathrm{kDa}$ (data not shown).

$\mathrm{N}$-Deprotection of $\mathbf{4}$ to yield the $\mathrm{O}$-modified cationic chitosan 5 was carried out using hydrazine, commonly employed for $\mathrm{N}$ -
Table 1

Elemental analysis data (\% C, N, O) as determined by XPS analysis of polymers 1-5. Polymer Atomic \%

\begin{tabular}{llll}
\cline { 2 - 4 } & $\mathrm{C}(1 \mathrm{~s})$ & $\mathrm{O}(1 \mathrm{~s})$ & $\mathrm{N}(1 \mathrm{~s})$ \\
\hline $\mathbf{1}$ & 58.5 & 33.6 & 7.9 \\
$\mathbf{2}$ & 67.4 & 27.6 & 5.0 \\
$\mathbf{3}$ & 66.8 & 26.3 & 7.0 \\
$\mathbf{4}$ & 65.6 & 25.8 & 8.7 \\
$\mathbf{5}$ & 62.3 & 27.9 & 9.9 \\
\hline
\end{tabular}

dephthaloylation of $\mathrm{N}$-phthaloyl-chitosan derivatives (Kurita et al., 2010). Again, given prior reports on significant breakdown of the chitosan's backbone in the course of $N$-dephthaloylation (Makuška \& Gorochovceva, 2006), we have run the deprotection for $18 \mathrm{~h}$ at only $40^{\circ} \mathrm{C}$. Structural analyses described below allowed confirming full removal of the $N$-phthaloyl protecting group to give polymer 5.

Finally, it should be noted that, in all cases, product polymers kept the fine powder structure of the starting materials, and no grinding was required in any step.

\subsection{Comparative analysis of chitosan (1) and its derivatives (2-5) by XPS}

Table 1 shows the relative atomic percentages of carbon, oxygen and nitrogen of unmodified chitosan (1) and chitosan derivatives (2-5), calculated from high resolution XPS spectra. The resolved XPS high resolution spectra of $\mathrm{C} 1 \mathrm{~s}, \mathrm{O} 1 \mathrm{~s}$ and N1s of unmodified chitosan and chitosan derivates can be visualized at Fig. 1. The relative atomic percentages of carbon in different environments, obtained from the C1s XPS high resolution spectra of unmodified and modified chitosan, are described in Table 2, whereas similar information referring to $01 \mathrm{~s}$ and $\mathrm{N} 1 \mathrm{~s}$ is given in Table 3 .

Results obtained for unmodified chitosan were as expected and agreed with data reported by other authors (Amaral, Granja, \& Barbosa, 2005; Beamson \& Briggs, 1992). The C1s spectrum of unmodified chitosan was fitted using three peaks as described elsewhere (Amaral, Granja, et al., 2005). The peak at $285.0 \mathrm{eV}$ was assigned to $\mathrm{C}-\mathrm{C}$ and $\mathrm{C}-\mathrm{H}$ type carbons mixed with $-\mathrm{CH}_{2}-$ from a surface contaminant (Amaral, Granja, et al., 2005); the peak at $286.4 \mathrm{eV}$ was assigned to $\mathrm{C}-\mathrm{NH}_{2}, \mathrm{C}-\mathrm{OH}$ and $\mathrm{C}-\mathrm{O}-\mathrm{C}$ carbons, whereas the peak at $281.1 \mathrm{eV}$ was assigned to carbons from the $\mathrm{O}-\mathrm{C}-\mathrm{O}$ and $\mathrm{N}-\mathrm{C}=\mathrm{O}$ groups. Regarding the resolved $\mathrm{O} 1 \mathrm{~s}$ spectrum, three peaks were indentified: at $531.6 \mathrm{eV}$, assigned to $\mathrm{N}-\mathrm{C}=\mathrm{O}$ in $\mathrm{N}$ acetylated glucosamine units and $\mathrm{CO}-\mathrm{N}-\mathrm{CO}$; at $532.8 \mathrm{eV}$, assigned to $\mathrm{C}-\mathrm{O}-\mathrm{C}$ and $\mathrm{C}-\mathrm{OH}$; and at $534.0 \mathrm{eV}$, assigned to $\mathrm{O}-\mathrm{C}-\mathrm{O}$. The resolved N1s spectrum revealed three peaks: at $399.7 \mathrm{eV}$, assigned to nitrogens in $\mathrm{C}-\mathrm{N}$ and $\mathrm{CO}-\mathrm{N}$ bonds; at $400.7 \mathrm{eV}$, assigned to $\mathrm{CO}-\mathrm{N}-\mathrm{CO}$ and $\mathrm{N}-\mathrm{CO}-\mathrm{O}$; and at $401.8 \mathrm{eV}$, assigned to amino groups in the ammonium form $\left(\mathrm{NH}_{3}{ }^{+}\right)$.

After $\mathrm{N}$-phthaloylation, i.e., regarding derivative $\mathbf{2}$ as compared to starting material $\mathbf{1}$, there was an increase in the atomic percentage of carbon accompanied by a small decrease in the percentages of nitrogen and oxygen, an expected consequence of the incorporation of the phthaloyl group. The increase of the peak at $285.0 \mathrm{eV}$ was ascribed to the insertion of $\mathrm{C}=\mathrm{C}$ type carbons from the phthaloyl group. Consequently, the carbon peak at $286.4 \mathrm{eV}$ has decreased due to the disappearance of $\mathrm{C}-\mathrm{NH}_{2}$ type carbons after $\mathrm{N}$-phthaloylation. Although the carbon peak at $288.1 \mathrm{eV}$ did not show any relevant change in intensity, a close inspection of this peak in Fig. 1 shows a small shift of the binding energy that could be related with insertion of $\mathrm{CO}-\mathrm{N}-\mathrm{CO}$ carbons. In the resolved $01 \mathrm{~s}$ spectrum, the increase of the peak at $531.6 \mathrm{eV}$ was ascribed to the insertion of $\mathrm{CO}-\mathrm{N}-\mathrm{CO}$ from the phthaloyl group. N1s XPS spectrum demonstrated the insertion of the phthaloyl group by the disappearance of the peak at $401.8 \mathrm{eV}$ 
01s
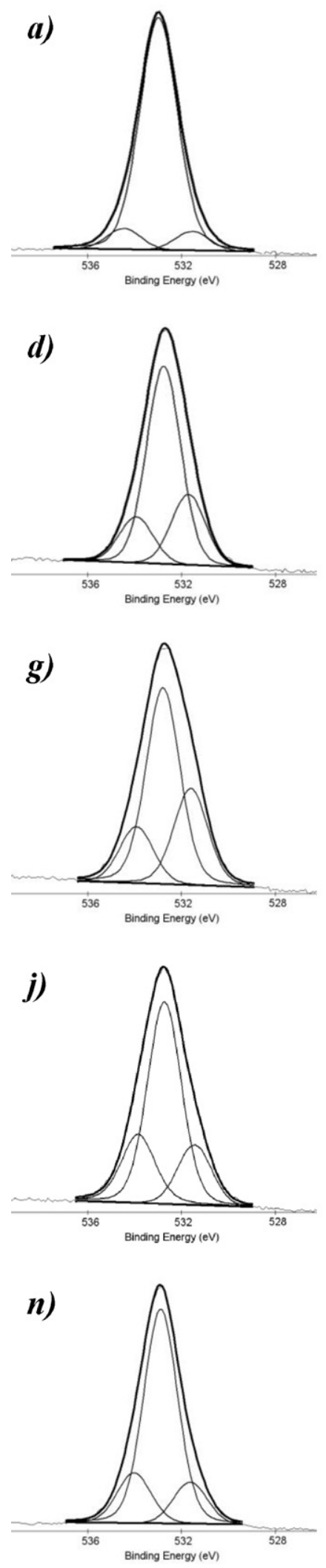

N1s
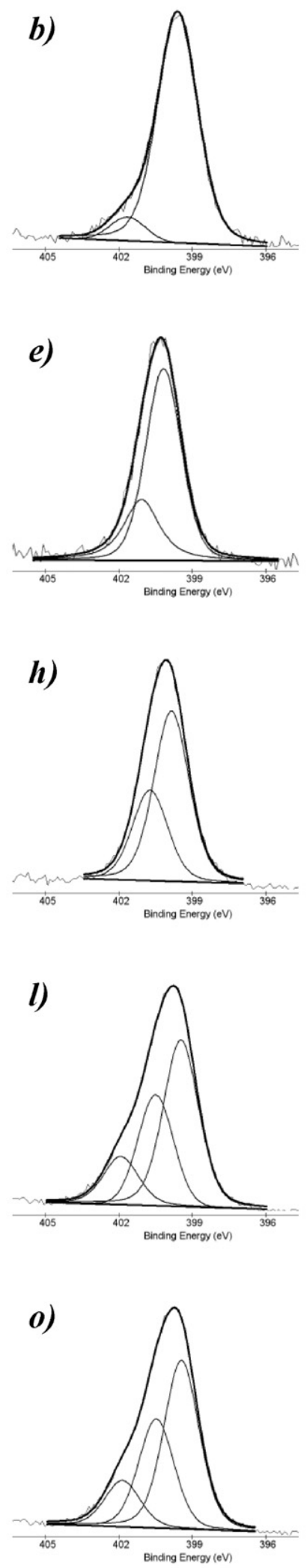

C1s
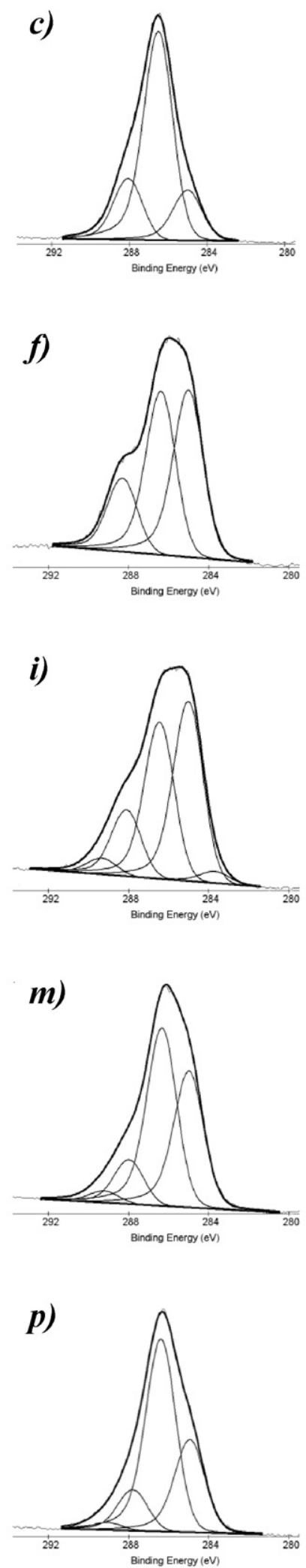

Polymer

\section{1}

2

3

4

\section{5}

Fig. 1. XPS high resolution spectra of: $(\boldsymbol{a}-\boldsymbol{c})$ unmodified chitosan $(\mathbf{1}) ;(\boldsymbol{d}-\boldsymbol{f}) N$-phthaloyl-chitosan $(\mathbf{2})$; $(\boldsymbol{g}$-i) $N$-phthaloyl-chitosan $O$-prop-2-ynyl carbamate 3; $(\boldsymbol{j}$-m) $N$ phthaloyl-chitosan $O$-(11-amino-3,6,9-undecan)triazolyl carbamate $\mathbf{4}$, and $(\boldsymbol{n}$-p $) O$-triazolyl chitosan $\mathbf{5}$ powders. O1s, N1s and C1s regions are shown. 
Table 2

$\mathrm{C}(1 \mathrm{~s})$ surface atomic composition of the different polymers 1-5.

\begin{tabular}{|c|c|c|c|c|c|}
\hline \multirow[t]{2}{*}{ Polymer } & \multicolumn{5}{|c|}{ Atomic \% C (1s) } \\
\hline & $\begin{array}{l}\mathrm{C} \equiv \mathrm{C} \\
283.7 \mathrm{eV}\end{array}$ & $\begin{array}{l}\mathrm{C}-\mathrm{C} / \mathrm{C}-\mathrm{H} / \mathrm{C}=\mathrm{C} \\
285 \mathrm{eV}\end{array}$ & $\begin{array}{l}\mathrm{C}-\mathrm{NH}_{2} / \mathrm{C}-\mathrm{OH} / \mathrm{C}-\mathrm{O}-\mathrm{C} \\
286.4 \mathrm{eV}\end{array}$ & $\begin{array}{l}\mathrm{O}-\mathrm{C}-\mathrm{O} / \mathrm{N}-\mathrm{C}=\mathrm{O} / \mathrm{CO}-\mathrm{N}-\mathrm{CO} \\
288.1 \mathrm{eV}\end{array}$ & $\begin{array}{l}\mathrm{N}-\mathrm{CO}-\mathrm{O} \\
289.2 \mathrm{eV}\end{array}$ \\
\hline 1 & - & 16 & 65 & 19 & - \\
\hline 2 & - & 42 & 40 & 18 & - \\
\hline 3 & 3 & 42 & 36 & 15 & 4 \\
\hline 4 & - & 38 & 48 & 11 & 3 \\
\hline 5 & - & 28 & 58 & 12 & 2 \\
\hline
\end{tabular}

Table 3

$\mathrm{O}(1 \mathrm{~s})$ and $\mathrm{N}(1 \mathrm{~s})$ surface atomic composition of the different polymers 1-5.

\begin{tabular}{|c|c|c|c|c|c|c|}
\hline \multirow[t]{2}{*}{ Polymer } & \multicolumn{3}{|l|}{ Atomic \% O (1s) } & \multicolumn{3}{|c|}{ Atomic \% N (1s) } \\
\hline & $\begin{array}{l}\mathrm{N}-\mathrm{C}=\mathrm{O} / \mathrm{CO}-\mathrm{N}-\mathrm{CO} \\
531.6 \mathrm{eV}\end{array}$ & $\begin{array}{l}\mathrm{C}-\mathrm{O}-\mathrm{C} / \mathrm{C}-\mathrm{OH} \\
532.8 \mathrm{eV}\end{array}$ & $\begin{array}{l}\mathrm{O}-\mathrm{C}-\mathrm{O} \\
534.0 \mathrm{eV}\end{array}$ & $\begin{array}{l}\mathrm{C}-\mathrm{N} / \mathrm{CO}-\mathrm{N} \\
399.7 \mathrm{eV}\end{array}$ & $\begin{array}{l}\mathrm{CO}-\mathrm{N}-\mathrm{CO} / \mathrm{N}-\mathrm{CO}-\mathrm{O} \\
400.7 \mathrm{eV}\end{array}$ & $\begin{array}{l}\mathrm{NH}_{3}{ }^{+} \\
401.8 \mathrm{eV}\end{array}$ \\
\hline 1 & 6 & 87 & 7 & 93 & - & 7 \\
\hline 2 & 22 & 64 & 14 & 72 & 28 & - \\
\hline 3 & 28 & 57 & 15 & 65 & 35 & - \\
\hline 4 & 17 & 61 & 22 & 52 & 32 & 16 \\
\hline 5 & 13 & 71 & 16 & 52 & 33 & 15 \\
\hline
\end{tabular}

assigned to $\mathrm{NH}_{3}{ }^{+}$and to the emergence of a new peak appeared at $400.7 \mathrm{eV}$, assigned to $\mathrm{CO}-\mathrm{N}-\mathrm{CO}$ and $\mathrm{N}-\mathrm{CO}-\mathrm{O}$ (Table 3).

As compared to its $\mathrm{N}$-phthaloyl chitosan 2 precursor, the $\mathrm{O}$ alkynyl derivative $\mathbf{3}$ presented a decrease in the percentages of carbon and oxygen along with a small increase in the percentage of nitrogen, compatible with insertion of propargylamine. The resolved C1s spectrum of 3 revealed two new peaks: one at $283.7 \mathrm{eV}$, assigned to the alkyne group $(\mathrm{C} \equiv \mathrm{C})$, and the other at $289.2 \mathrm{eV}$ ascribed to the carbamate group ( $\mathrm{N}-\mathrm{CO}-\mathrm{O})$. The decrease of the peak relative intensity at $286.4 \mathrm{eV}$ was compatible with partial modification of the $\mathrm{C}-\mathrm{OH}$ type carbons. For the $\mathrm{O} 1 \mathrm{~s}$ surface atomic percentage, there was a small increase of the peak at $531.6 \mathrm{eV}$, due to $\mathrm{N}-\mathrm{C}=\mathrm{O}$ from the carbamate bond formed. In the resolved N1s spectrum, the expected increase of the peak at $400.7 \mathrm{eV}$, ascribed to the carbamate group ( $\mathrm{N}-\mathrm{CO}-\mathrm{O})$, was also observed.

XPS analysis of $N$-phthaloyl-chitosan $O$-(11-amino-3,6,9undecan)triazolyl carbamate (4) showed a decrease in the percentages of carbon and oxygen and concomitant increase in the percentage of nitrogen, supporting the occurrence of the desired azide-alkyne coupling to yield a triazole structure. When the $\mathrm{C} 1 \mathrm{~s}$ spectrum of $\mathbf{4}$ is compared to that of its precursor $\mathbf{3}$, the carbon peak at $283.7 \mathrm{eV}$ disappears, which by itself demonstrates the conversion of the $\mathrm{C} \equiv \mathrm{C}$ group into something different. Furthermore, an increase of the peak at $286.4 \mathrm{eV}$ can be ascribed to the insertion of additional $\mathrm{C}-\mathrm{O}-\mathrm{C}$ type carbons, present in the PEG-like chain from the azide used in the cycloaddition. This was also observed in the resolved $01 \mathrm{~s}$ spectrum, from peaks at $532.8 \mathrm{eV}$ and $534.0 \mathrm{eV}$, due to $\mathrm{C}-\mathrm{O}-\mathrm{C}$ and $\mathrm{O}-\mathrm{C}-\mathrm{O}$ bonds, respectively, which increase upon insertion of the PEG-like chain. For the resolved N1s spectrum, the peak at $401.8 \mathrm{eV}$, due to $\mathrm{NH}_{3}{ }^{+}$, reappears as a consequence of insertion of the amino-terminated ligand.

Finally, XPS analysis revealed that the dephthaloylation reaction to give polymer $\mathbf{5}$ led to a decrease in the atomic percentage of carbon along with an increase in the atomic percentage of all the other elements, as expected from the removal of the phthaloyl group. This interpretation was supported by the almost complete disappearance of the peak at $285 \mathrm{eV}$ ( $\mathrm{C}=\mathrm{C}$ type carbons) together with a clear increase in the relative intensity of the peak at $286.4 \mathrm{eV}\left(\mathrm{C}-\mathrm{O}-\mathrm{C}+\mathrm{C}-\mathrm{NH}_{2}\right.$ type carbons). In the resolved $\mathrm{O} 1 \mathrm{~s}$ spectrum, the expected decrease of the peak at $531.6 \mathrm{eV}$ ascribed to
CO-N-CO was observed, due to phthaloyl removal. For the resolved $\mathrm{N} 1 \mathrm{~s}$ spectrum, only changes on relative atomic percentages were observed, since the types of nitrogen atoms already present in precursor 4 remained the same after dephthaloylation to give 5.

\subsection{Analysis of chitosan (1) and its derivatives (2-5) by FT-IR}

FT-IR was also used to monitor the structural changes caused by the stepwise chemical modification of chitosan (1) all the way through intermediate polymers $\mathbf{2 - 4}$ until the final cationic polymer 5. The obtained infrared spectra are thus displayed in Figs. 2 and 3.

The IR spectrum (Fig. 2) of unmodified chitosan (1) presented the expected characteristic bands (Gomes, Gomes, Batista, Pinto, \& Silva, 2008), like: broad intense band at $3450-3200 \mathrm{~cm}^{-1}$ due to overlapping contributions of different hydrogen-bonded $\mathrm{X}-\mathrm{H}$ stretching vibrations, as $\mathrm{O}-\mathrm{H}$ stretching at $3426 \mathrm{~cm}^{-1}, \mathrm{NH}_{2}$ asymmetric stretching at $3377 \mathrm{~cm}^{-1}$ and N-H stretching at $3303 \mathrm{~cm}^{-1}$; $\mathrm{C}-\mathrm{H}$ stretching at $2878 \mathrm{~cm}^{-1}$; characteristic vibration modes from GlcNHAc units, as amide I at $1656 \mathrm{~cm}^{-1}$ ( $\mathrm{C}=\mathrm{O}$ stretching from sec-

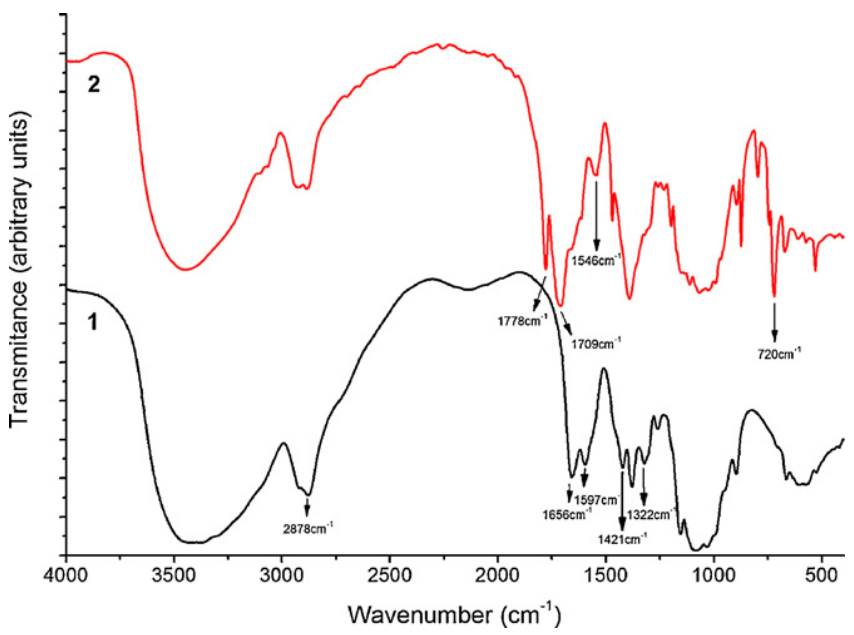

Fig. 2. FT-IR spectra ( $\mathrm{KBr}$ pellets) of (1) unmodified chitosan and (2) N-phthaloyl chitosan powders. 


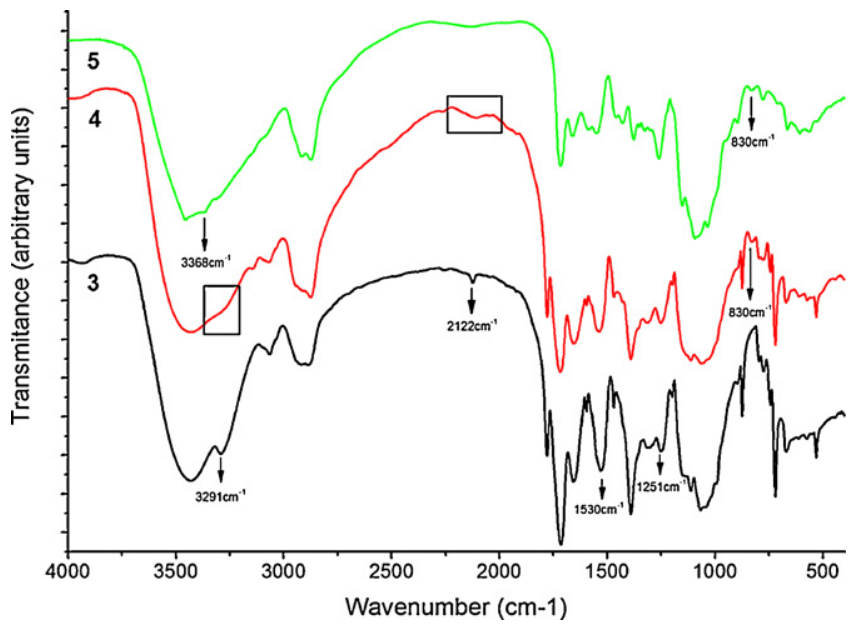

Fig. 3. FT-IR spectra ( $\mathrm{KBr}$ pellets) of (3) $\mathrm{N}$-phthaloyl-chitosan $O$-prop-2-ynyl carbamate, (4) $N$-phthaloyl-chitosan $O$-(11-amino-3,6,9-undecan)triazolyl carbamate and (5) chitosan $O$-(11-amino-3,6,9-undecan)triazolyl carbamate powders.

ondary amides), amide II (in plane $\mathrm{N}-\mathrm{H}$ deformation coupled with $\mathrm{C}-\mathrm{N}$ stretching from secondary amides) and the $\mathrm{N}-\mathrm{H}$ bending of the primary amine at $1597 \mathrm{~cm}^{-1}$, amide III at $1322 \mathrm{~cm}^{-1}$ (C-N stretching) and $-\mathrm{CH}_{3}$ symmetrical angular deformation at $1378 \mathrm{~cm}^{-1}$; $\mathrm{O}-\mathrm{H}$ plane deformation (primary alcohol) at $1421 \mathrm{~cm}^{-1}$; C-O-C stretching vibration in the glucopyranose ring at $1032 \mathrm{~cm}^{-1}$; and the specific bands of the $\beta(1-4)$ glycoside bridge at 1153 and $897 \mathrm{~cm}^{-1}$ (Socrates, 2001). The IR spectrum (Fig. 2) of $\mathrm{N}-$ phthaloyl chitosan (2) displayed additional peaks with respect to the unmodified chitosan, characteristic of the phthalimide group (Socrates, 2001) inserted: two $\mathrm{C}=\mathrm{O}$ stretching bands at 1778 and $1709 \mathrm{~cm}^{-1}$ and imide $\mathrm{C}=\mathrm{C}$ stretching at $1551 \mathrm{~cm}^{-1} ;=\mathrm{C}-\mathrm{H}$ out of plane deformation at $720 \mathrm{~cm}^{-1}$ and aromatic ring deformation at $530 \mathrm{~cm}^{-1}$ from the aromatic ring of the phthaloyl group. These observations were in agreement with previously reported data on similar $N$-phthaloyl chitosan derivatives developed by Kurita et al. (2002).

The IR spectrum (Fig. 3) of $\mathrm{N}$-phthaloyl-chitosan $\mathrm{O}$-prop-2-ynyl carbamate, 3 , herein proposed as a novel "clickable" chitosan, exhibited the following additional peaks: $\equiv \mathrm{C}-\mathrm{H}$ stretching vibration at $3291 \mathrm{~cm}^{-1}$ and $\mathrm{C} \equiv \mathrm{C}$ stretching vibration at $2122 \mathrm{~cm}^{-1}$, typical of monosubstituted alkynes (Socrates, 2001); absorption due to $\mathrm{CHN}$ group ( $\mathrm{N}-\mathrm{H}$ deformation and $\mathrm{C}-\mathrm{N}$ stretching) at $1530 \mathrm{~cm}^{-1}$ and coupled $\mathrm{C}-\mathrm{N}$ and $\mathrm{C}-\mathrm{O}$ stretching vibration at $1251 \mathrm{~cm}^{-1}$, from the carbamate group. These features were in complete agreement with formation of $\mathrm{N}$-phthaloyl-chitosan $\mathrm{O}$ prop-2-ynyl carbamate, 3.

After reacting polymer $\mathbf{3}$ with the PEG-like azide under classical azide-alkyne coupling conditions, the triazolyl derivative 4 was obtained, whose FT-IR spectrum (Fig. 2) displayed two relevant changes, as compared to its precursor (3); a band at $830 \mathrm{~cm}^{-1}$, characteristic of $\mathrm{N}-\mathrm{C}=\mathrm{N}$ in plane bending (Krishnakumar \& John Xavier, 2004), arising from formation of the triazole ring; additional evidence of the occurrence of the azide-alkyne coupling was provided by the disappearance of the typical monosubstituted alkyne vibration modes at $3291 \mathrm{~cm}^{-1}\left(\equiv \mathrm{C}-\mathrm{H}\right.$ stretching) and $2122 \mathrm{~cm}^{-1}(\mathrm{C} \equiv \mathrm{C}$ stretching). Given the structural nature of the azide used in the cycloaddition, i.e., of its 3,6,9-trioxaundecan-1-amine backbone, all additional vibration modes from this backbone were expectedly overlapped to similar modes already present on the precursor polymeric matrix.

Final deblocking of the primary amines by dephthaloylation led to 5, whose FT-IR spectrum (Fig. 2) revealed the expected features, i.e., disappearance of the aforementioned phthaloyl-related bands, i.e., $C=O$ stretching above $1700 \mathrm{~cm}^{-1}$, imide $C=C$ stretching at $\sim 1550 \mathrm{~cm}^{-1}$; $=\mathrm{C}-\mathrm{H}$ out of plane deformation at $720 \mathrm{~cm}^{-1}$ and aromatic ring deformation at $530 \mathrm{~cm}^{-1}$ and as well describe previously the appearance of the peak characteristic of $\mathrm{NH}_{2}$ asymmetric stretching at $3368 \mathrm{~cm}^{-1}$ with preservation of the remaining spectral features.

Overall, FT-IR analysis of the five polymers was in agreement with XPS-derived data, providing further confirmation that the chemical route depicted on Scheme 1 was suitable to introduce the desired modifications onto chitosan.

\subsection{Characterization of polymers 1-5 by SSNMR}

Due to its ability to probe locally and selectively the chemical environment of each carbon nucleus, SSNMR spectroscopy was used to unambiguously identify each chitosan derivative with high accuracy. Fig. 4 shows the ensemble of the SSNMR results using the ${ }^{13} \mathrm{C}-\mathrm{CP} / \mathrm{MAS}$ NMR method. The ${ }^{13} \mathrm{C}-\mathrm{CP} / \mathrm{MAS}$ NMR spectrum of 1 (Fig. 4a) shows that the starting biopolymer has, as its main component, chitosan residues identified by the ${ }^{13} \mathrm{C}$ resonances observed at carbon chemical shifts, $\delta \sim 105.4$ (C1), 57.2 (C2), 75.1 (C3, C5), 83.1 (C4) and 60.8 (C6) ppm. Two additional ${ }^{13} \mathrm{C}$ resonances may be observed at $\delta \sim 173.7$ and $23.5 \mathrm{ppm}$, which are assigned to the carbonyl $\left(\mathrm{C7}^{\prime}\right)$ and methyl $\left(\mathrm{C}^{\prime}\right)$ functional groups typically present in the chitin skeleton. Upon reaction of $\mathbf{1}$ with phthalic anhydride, polymer $\mathbf{2}$ was obtained (Scheme 1 ). The structure of polymer 2 may be easily confirmed by the observation of three ${ }^{13} \mathrm{C}$ resonances typical of the $N$-phthaloyl substituent appearing at $\delta \sim 168.9,134.7,131.0$ and $123.4 \mathrm{ppm}$, which correspond to the C7, C10, C8 and C9 carbon atoms, respectively (Fig. 4b), and agrees with data previously reported (Kurita et al., 2002). The acetyl ${ }^{13} \mathrm{C}$ resonances from chitin may still be observed $\left(C 7^{\prime}\right)$. Polymer 3, obtained after coupling $\mathbf{2}$ with propargylamine, may be also straightforwardly detected, by the presence of the ${ }^{13} \mathrm{C}$ resonances typical of the propargyl substituent ( $R$ group in Fig. $4 \mathrm{c}$ ). For example, ${ }^{13} \mathrm{C}$ peaks observed at $\delta \sim 157.0$ and $30.7 \mathrm{ppm}$ are assigned to the amide carbonyl $[\mathrm{C}(1)]$ and to the $\mathrm{N}-\mathrm{CH}_{2}$ carbon $[\mathrm{C}(2)]$, respectively. The carbons involved in the triple bond are superimposed with the ${ }^{13} \mathrm{C}$ resonances from the chitosan skeleton observed in the region between $\delta \sim 70$ and $85 \mathrm{ppm}$, hampering their individual assignment.

SSNMR also confirmed that polymer $\mathbf{3}$ was converted into $\mathbf{4}$ through the Huisgen's 1,3-dipolar cycloaddition performed, with concomitant formation of a triazole ring at positions $\mathrm{C} 6$ and $\mathrm{C}^{\prime}$. This is clearly shown by the ${ }^{13} \mathrm{C}$ resonances at $\delta \sim 50.9,40.1$ and $36.8 \mathrm{ppm}$, which do not appear in the previous ${ }^{13} \mathrm{C}-\mathrm{CP} / \mathrm{MAS}$ NMR spectra of 1-3 (Fig. 4a-c). These three resonances are assigned to C[5], C[2] and C[7] carbons from the triazole substituent $\left(R_{1}\right)$. It is worth mentioning that two additional ${ }^{13} \mathrm{C}$ peaks from the $R_{1}$ moiety, resonating at $\delta \sim 156.7$ and $145.4 \mathrm{ppm}$, are also observed at higher chemical shifts. The former peak is assigned to the $C=O(C[1]$; $156.7 \mathrm{ppm}$ ) from the $R_{1}$ side-chain in configuration $\mathrm{A}$, while the latter resonance is assigned to the $\mathrm{C}=\mathrm{O}\left(\mathrm{C}[3]^{*} ; 145.4 \mathrm{ppm}\right)$, which belong to the $R_{1}$ substituent following the arrangement adopted in configuration B (Fig. 4d). SSNMR was, thus, the only method that allowed to discriminate between both configurations existent in polymer 4 . This fact is a consequence of the two possible orientations at which the azide-alkyne cycloaddition may take place, i.e., the formation of both the 1,4 and 1,5 cycloaddition adducts (Kolb, Finn \& Sharpless, 2001; Meldal \& Tomøe, 2008). This particular finding further demonstrates the occurrence of the desired cycloaddition, which converted the $O$-alkynylated chitosan 3 into the $O$-triazolyl conjugate 4.

Finally, SSNMR analysis of polymer 5 showed that the $\mathrm{N}$ phthaloyl protecting group, present in $\mathbf{4}$, was removed as desired. 


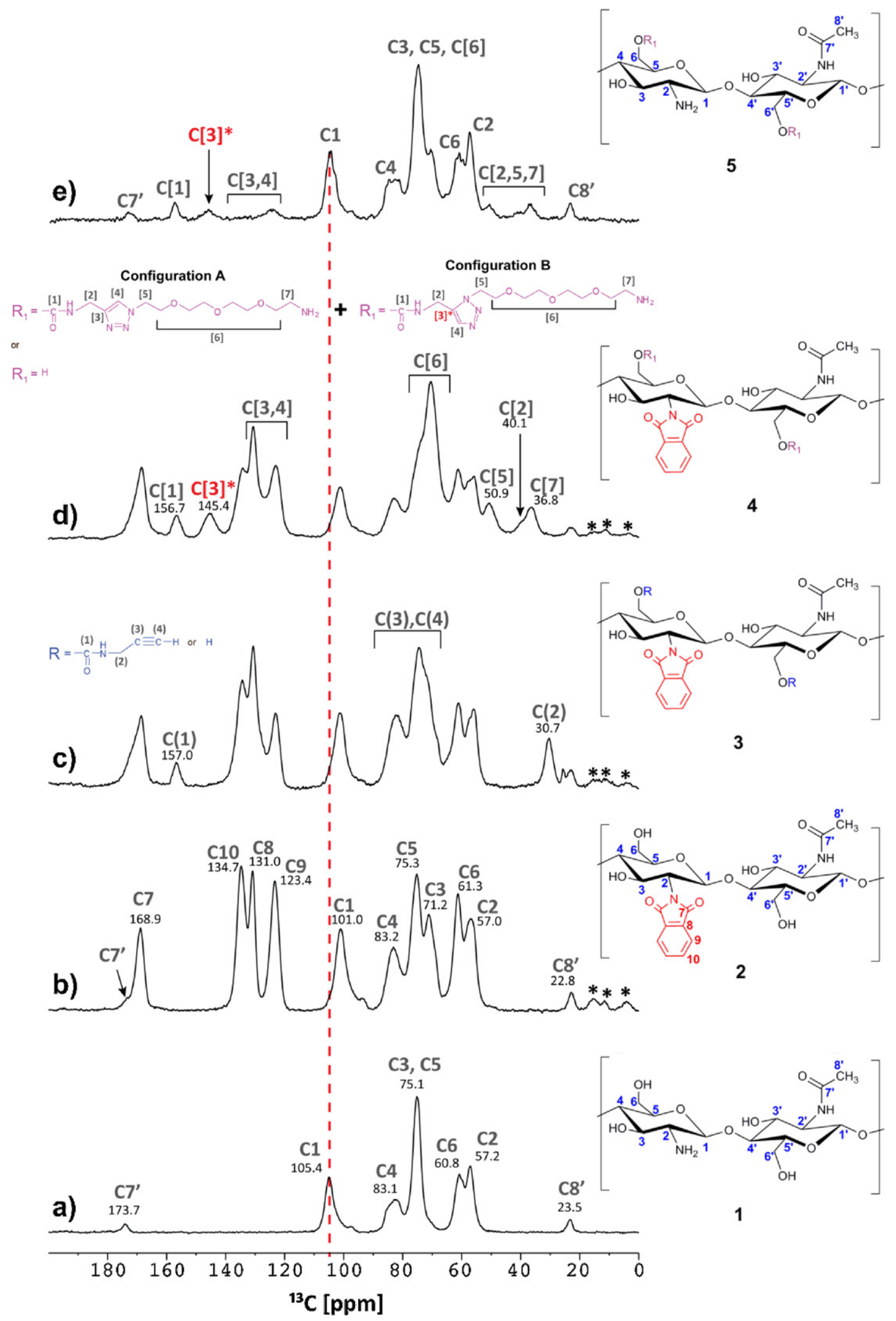

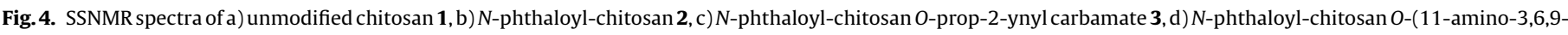

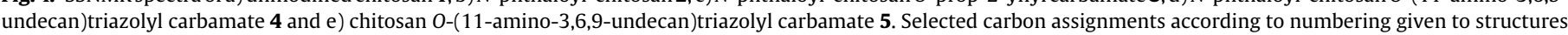
shown on the right. Asterisks depict spinning sidebands.

Complete removal of this group may be confirmed by the disappearance of the four ${ }^{13} \mathrm{C}$ resonances $(\mathrm{C} 7-10)$ at $\delta \sim 168.9,131.0$, 123.4 and 134.7 ppm (Fig. $4 \mathrm{~b}-\mathrm{d}$ ). The ${ }^{13} \mathrm{C}$ spectrum of 5 is essentially the same as the ${ }^{13} \mathrm{C}$ spectrum of $\mathbf{1}$ excluding the additional peaks observed in $\mathbf{5}$ (Fig. 4e) due to the $R_{1}$ substituent. Notice that the anomeric carbon (C1) resonances observed in the spectrum of the chitosan monomer in $\mathbf{1}$ and $\mathbf{5}$ ( $c f$. Fig. 4a and e emphasized by the red dashed line) have the same chemical shifts, while in all the other 
${ }^{13} \mathrm{C}$ spectra (Fig. $4 \mathrm{~b}-\mathrm{d}$ ) the chemical shift position of $\mathrm{C} 1$ carbons are slightly shifted to higher fields due to the effect of the $\mathrm{N}$-phthaloyl protecting group attached to the nearby $\mathrm{C} 2$ carbon atom.

In conclusion, it is demonstrated that the final polymer, 5, is obtained free of any detectable impurities, bearing its $R_{1}$ group in two different configurations and having an amine group at position $\mathrm{C} 2$, which proves that $\mathbf{5}$ no longer contains the $\mathrm{N}$-phthaloyl amine protecting group at that position.

\section{Concluding remarks}

Straightforward chemistry was employed for the synthesis of $\mathrm{N}$ phthaloyl-chitosan $O$-prop-2-ynyl carbamate, proposed as a novel polymer that may be conjugated to other [bio]molecules by a chemoselective azide-alkyne coupling, while preserving bioadhesion and $p H$-dependent properties associated to chitosan's primary amines. This polymer was then conjugated, by means of the Huisgen's 1,3-dipolar cycloaddition (azide-alkyne coupling) with a model azide (PEG-like azide), producing a stable triazole linkage compatible with subsequent removal of the amine-protecting group, to recover the original chitosan's primary amines that are responsible for many of the attractive features of this biopolymer. The structures of all starting, intermediate and final materials were characterized and confirmed by means of different analysis techniques, i.e., XPS, FT-IR and SSNMR, all of them in perfect agreement with each other.

The low solubility of the polymers obtained in either aqueous or organic media gives them potential for topical applications, e.g., treatment of infected skin wounds (Batista, Gallemí, Adeva, Gomes, \& Gomes, 2009; Dai, Tegos, Burkatovskaya, Castano, \& Hamblin, 2009) or transdermal gene delivery (Özbaş-Turan, Akbuğa, \& Sezer, 2010) or immunization (Prabuh, Sundaramoorthi, Selvaraju, \& Tamilselvi, 2011). Properly modified insoluble chitosans are also interesting for removal of toxic substances from either the body (Park, Kwon, Choi, \& Kim, 2000) or environmental sources (Bhatnagar \& Sillanpää, 2009).

There is a growing number of commercially available molecules bearing an azide moiety for click conjugations. So, a chitosan derivative as $N$-phthaloyl-chitosan $O$-prop-2-ynyl carbamate, $\mathbf{3}$, may serve as a polymer template for chemoselective coupling to any azide, for tailored applications and properties.

\section{Acknowledgments}

The authors thank Fundação para a Ciência e Tecnologia (FCT, Portugal) and FEDER (European Union) for co-funding this project (ref. PTDC/CTM/65330/2006 and ref. FCOMP-01-0124-FEDER007135). PG thanks FCT for pluri-annual funding to Research Unit CIQUP. LM acknowledges FCT for financing the Portuguese NMR network (ref. REDE/1517/RMN/2005) and the project PTDC/QUIQUI/100998/2008, which allowed the use of the NMR facilities, efficiently. The authors are also indebted to Drs. Cristina Barrias (INEB) and Eliandre de Oliveira (Parc Científic de la Universitat de Barcelona, Spain) for collaboration in molecular weight analysis by HP-SEC and MALDI-TOF MS, respectively.

\section{References}

Amaral, I. F., Granja, P., \& Barbosa, M. A. (2005). Chemical modification of chitosan by phosphorylation: an XPS, FT-IR and SEM study. Journal of Biomaterials Science, Polymer Edition, 16, 1575-1593.

Amaral, I. F., Lamghari, M., Sousa, S. R., Sampaio, P., \& Barbosa, M. A. (2005). Rat bone marrow stromal cell osteogenic differentiation and fibronectin adsorption on chitosan membranes: the effect of the degree of acetylation.Journal of Biomedical Materials Research, 75A, 387-397.

Anitha, A., Deepa, N., Chennazhi, K. P., Nair, S. V., Tamura, H., \& Jayakumar, R. (2011). Development of muchoadhesive, thiolated chitosan nanoparticles for biomedical applications. Carbohydrate Polymers, 83, 66-73.
Batista, M. K. S., Gallemí, M., Adeva, A., Gomes, C. A. R., \& Gomes, P. (2009). Facile regioselective synthesis of a novel chitosan-pexiganan conjugate with potential interest for the treatment of infected skin lesions. Synthetic Communications, 39 1228-1240.

Batista, M. K. S., Pinto, L. F., Gomes, C. A. R., \& Gomes, P. (2006). Novel highly-soluble peptide-chitosan polymers: synthesis and spectral characterization. Carbohydrate Polymers, 64, 299-305.

Beamson, G., \& Briggs, D. (1992). High Resolution XPS of Organic Polymers: The Scientia ESCA300 Database. New York (USA): John Wiley \& Sons.

Bennett, A. E., Rienstra, C. M., Auger, M., Lakshmi, K. V., \& Griffin, R. G. (1995). Heteronuclear decoupling in rotating solids. The Journal of Chemical Physics, 103 6951-6958.

Berger, J., Reist, M., Mayer, J. M., Felt, O., \& Gurny, R. (2004). Structure and interactions in chitosan hydrogels formed by complexation or aggregation for biomedical applications. European Journal of Pharmaceutics and Biopharmaceutics, 57, $35-52$.

Berger, J., Reist, M., Mayer, J. M., Felt, O., Peppas, N. A., \& Gurny, R. (2004). Structure and interactions in covalently and ionically crosslinked chitosan hydrogels for biomedical applications. European Journal of Pharmaceutics and Biopharmaceutics, 57, 19-34.

Bhatnagar, A. \& Sillanpää, M. (2009). Applications of chitin- and chitosan-derivatives for the detoxification of water and wastewater: a short review. Advances in Colloid and Interface Science, 152, 26-38.

Brugnerotto, J., Lizardi, J., Goycoolea, F. M., Argüelles-Monal, W., Desbrières, J., \& Rinaudo, M. (2001). An infrared investigation in relation with chitin and chitosan characterization. Polymer, 42, 3569-3580.

Cabrera, J. C., \& Van Cutsem, P. (2005). Preparation of chitooligosaccharides with degree of polymerization higher than 6 by acid or enzymatic degradation of chitosan. Biochemical Engineering Journal, 25, 165-172.

Chinchilla, R., \& Nájera, C. (2007). The Sonogashira reaction: a booming methodology in synthetic organic chemistry. Chemical Reviews, 107, 874-922.

Chirachanchai, S., Lertworasirikul, A., \& Tachaboonyakiat, W. (2001). Carbaryl insecticide conjugation onto chitosan via iodochitosan and chitosan carbonyl imidazolide precursors. Carbohydrate Polymers, 46, 19-27.

Crompton, K. E., Goud, J. D., Bellamkonda, R. V., Gengenbach, T. R., Finkelstein, D. I., Horne, M. K., et al. (2007). Polylysine-functionalised thermoresponsive chitosan hydrogel for neural tissue engineering. Biomaterials, 28 , 441-449.

Dai, T., Tegos, G. P., Burkatovskaya, M., Castano, A. P., \& Hamblin, M. R. (2009). Chitosan acetate bandage as a topical antimicrobial dressing for infected burns. Antimicrobial Agents and Chemotherapy, 53, 393-400.

Elkholy, S. S., Khalil, K. D., \& Elsabee, M. Z. (2011). Grafting of acryloyl cyanoacetohydrazide onto chitosan. Journal of Polymer Research, 18, 459-467.

Gomes, P., Gomes, C. A. R., Batista, M. K. S., Pinto, L. F., \& Silva, P. A. P. (2008). Synthesis, structural characterization and properties of water-soluble $\mathrm{N}-(\gamma$-propanoylamino acid)-chitosans. Carbohydrate Polymers, 71, 54-65.

Holappa, J., Hjálmarsdóttir, M., Másson, M., Rúnarsson, Ö., Asplund, T., Soininen, P., et al. (2006). Antimicrobial activity of chitosan $\mathrm{N}$-betainates. Carbohydrate Polymers, 65, 114-118.

Holappa, J., Nevalainen, T., Soininen, P., Másson, M., \& Järvinen, T. (2006) Synthesis of novel quaternary chitosan derivatives via $\mathrm{N}$-chloroacyl-6-Otriphenylmethylchitosans. Biomacromolecules, 7, 407-410.

Iqbal, J., Sarti, F., Perera, G., \& Bernkop-Schnürch, A. (2011). Development and in vivo evaluation of an oral drug delivery system for paclitaxel. Biomaterials, $32,170-175$.

Kolb, H. C., Finn, M. G., \& Sharpless, K. B. (2001). Click Chemistry: diverse chemica function from a few good reactions. Angewandte Chemie International Edition, 40 2004-2021.

Krishnakumar, V., \& John Xavier, R. (2004). FT Raman and FT-IR spectral studies of 3 mercapto-1,2,4-triazole. Spectrochimica Acta-PartA:Molecular and Biomolecular Spectroscopy, 60, 709-714.

Kulbokaite, R., Ciuta, G., Netopilik, M., \& Makuska, R. (2009). N-PEGylation of chitosan via click reactions. Reactive and Functional Polymers., 69, 771-778.

Kurita, K., Ikeda, H., Yoshida, Y., Shimojoh, M., \& Harata, M. (2002). Chemoselective protection of the amino groups of chitosan by controlled phthaloylation: facile preparation of a precursor useful for chemical modifications. Biomacromolecules $3,1-4$

Kurita, K., Yoshida, Y., \& Umemura, T. (2010). Finely selective protections and deprotections of multifunctional chitin and chitosan to synthesize key intermediates for regioselective chemical modifications. Carbohydrate Polymers, 81, 434-440.

Lahann, J. (2009). Click Chemistry for Biotechnology and Materials Science. Chichester (UK): John Wiley \& Sons.

Lallana, E., Fernández-Megía, E., \& Riguera, R. (2009). Surpassing the use of coppe in the click functionalization of polymeric nanostructures: a strain promoted approach. Journal of the American Chemical Society., 131, 5748-5750.

Li, X., Yuan, W., Gu, S., \& Re, J. (2010). Synthesis and self-assembly of tunable thermosensitive chitosan amphiphilic copolymers by click chemistry. Materials Letters, 64, 2663-2666.

Makuška, R., \& Gorochovceva, N. (2006). Regioselective grafting of poly(ethylene glycol) onto chitosan through C-6 position of glucosamine units. Carbohydrate Polymers, 64, 319-327.

Meldal, M., \& Tomøe, C. W. (2008). Cu-catalyzed azide-alkyne cycloaddition. Chem ical Reviews, 108, 2952-3015.

Molnár, E., Barbu, E., Lien, C.-F., Górecki, D. C., \& Tsibouklis, J. (2010). Toward drug delivery into the brain: synthesis, characterization, and preliminary in vitro 
assessment of alkylglyceryl-functionalized chitosan nanoparticles. Biomacromolecules, 11, 2880-2889.

Montalbetti, C. A. G. N., \& Falque, V. (2005). Amide bond formation and peptide coupling. Tetrahedron, 61, 10827-10852.

Muzzarelli, R. A. A. (1988). Carboxymethylated chitins and chitosans. Carbohydrate Polymers, 8, 1-21.

Muzzarelli, R. A. A. (2009). Chitins and chitosans for the repair of wounded skin, nerve, cartilage and bone. Carbohydrate Polymers, 76, 167-182.

Muzarelli, R. A. A. (2011). Chitosan composites with inorganics, morphogenetic proteins and stem cells, for bone regeneration. Carbohydrate Polymers, 83, 1433-1445.

Oh, J. K., Lee, D. I., \& Park, J. M. (2009). Biopolymer-based microgels/nanogels for drug delivery applications. Progress in Polymer Science, 34, 1261-1282.

Önal, S., \& Telefoncu, A. (2003). Comparison of chitin and amberlite IRA-938 for agalactosidase immobilization. Artifical Cells, Blood Substitutes, and Biotechnology, 31, 19-33.

Özbaş-Turan, S., Akbuğa, J., \& Sezer, A. D. (2010). Topical application of antisense oligonucleotide-loaded chitosan nanoparticles to rats. Oligonucleotides, $20,147-153$

Park, S. O., Kwon, O. S., Choi, C. W., \& Kim, C.-J. (2000). Glucosamine-mediated detoxification of $p$-benzoquinone and its removal by chitosan. Biotechnology Letters, 22, 21-24.

Prabuh, K., Sundaramoorthi, V., Selvaraju, C. K., \& Tamilselvi, K. K. N. (2011). Topical immunization and the use of chitosan as carrier. International Journal of Research in Ayurveda and Pharmacy, 2, 90-94.

Shen, X., Ji, Y., Yang, Q., \& Zheng, X. (2007). Preparation, characterization, and rheological properties of dibutyrylchitin. Journal of Macromolecular Science B, 49 $250-258$.
Socrates, G. (2001). Infrared and Raman Characteristic Group Frequencies Tables and Charts (3rd edition). New York (USA): John Wiley \& Sons, Ltd.

Rúnarsson, Ö., Holappa, J., Jónsdóttir, S., Steinsson, H., \& Másson, M. (2008). Nselective 'one-pot' synthesis of highly substituted trimethyl chitosan (TMC). Carbohydrate Polymers, 74, 740-744.

Rúnarsson, Ö., Holappa, J., Malainer, C., Steinsson, H., Hjálmarsdóttir, M., Nevalainen, T., et al. (2010). Antibacterial activity of $N$-quaternary chitosan derivatives: synthesis, characterization and structure activity relationship (SAR) investigations. European Polymer Journal, 46, 1251-1267.

Wan, A., Gao, Q., \& Li, H. (2010). Effects of molecular weight and degree of acetylation on the release of nitric oxide from chitosan-nitric oxide adducts. Journal of Applied Polymer Science, 117, 2183-2188.

Yuan, W., Li, X., Gu, S., Cao, A., \& Ren, J. (2011). Amphiphilic chitosan graft copolymer via combination of ROP, ATRP and click chemistry: synthesis, selfassembly, thermosensitivity, fluorescence, and controlled drug release. Polymer, 52, 658-666.

Yuan, W., Zhao, Z., Gu, S., \& Ren, J. (2010). Synthesis, characterization, and properties of amphiphilic chitosan copolymers with mixed side chains by click chemistry. Journal of Polymer Science A, 48, 3476-3486.

Yuan, W., Zhao, Z., Gu, S., Ren, T., \& Ren, J. (2011). Synthesis and self-assembly of $\mathrm{pH}$-responsive chitosan graft copolymer by the combination of atom transfer radical polymerization and click chemistry. Materials Letters, 65, 793-796.

Zhang, J., Li, C., Xue, Z.-Y., Cheng, H.-W., Huang, F.-W., Zhuo, R.-X., et al. (2011). Fabrication of lactobionic-loaded chitosan microcapsules as potential drug carriers targeting the liver. Acta Biomaterialia, 7, 1665-1673. 